\title{
Millenium money for Japanese scientists
}

Japanese life scientists are to receive $¥ 98.5$ billion (US\$850 million) in additional funding under a special appropriation called the "Millennium Project" in next year's science budget. Set up under the direction of the Japanese Prime Minister, Keizo Obuchi, the Project aims to fund science and technology programs with a high potential for stimulating long-term economic growth-commercially applicable research. The Diet (Parliament) is expected to approve the budget request at the beginning of 2000 .

In addition to supporting large projects at the Ministry of International Trade and Industry (MITI) and the Ministry of Health and Welfare (MHW), such as the development of singlenucleotide polymorphism (SNP) libraries specific for the Japanese population to be accessed by Japanese pharmaceutical companies, some of the money will fund biotechnology start-up companies as part of the country's initiative to become more internationally competitive in biotechnology and genomics.

With its share of the Millenium funds, the Ministry of Education plans to increase the number of tenured positions at major university-based life science research centers. Special schemes for neuroscience, cancer and aging research will be created within the ministry's grants-in-aid program-the principal funding source for university based research in Japan.

The Science and Technology Agency (STA), which will merge with the Ministry of Education in 2001, is planning a sub-

group at the STA, chaired by Hiroo Imura, a former president of Kyoto University and a permanent member of the Council for Science and Technology, uncertainty surrounds their agenda.

Some observers in Tokyo are questioning the rationale of setting up a second genetics facility and an SNP program at RIKEN separate from that at MITI. And although the move to reinforce research in developmental biology seems to have been motivated by recent breakthroughs in human stemcell research, it is not yet clear to what extent the Japanese government will fund stem cell research. In fact, members of an ethics sub-committee under the Council for Science and Technology are still working on guidelines for human embryo research, and say that they were surprised and felt bypassed when they were told of the STA's intention to fund such studies using the Millennium money. This prompted STA officials to reaffirm that a decision on the research strategy for the institute would be worked out only after the new human embryo guidelines become available.

Although many scientists welcome the new initiatives, some warn of an increasing concentration of research funding within a few laboratories in the Tokyo area. Still others say they fear the new programs could be too heavily tilted towards applied research: Yumiko Saga, a developmental biologist at the National Institute of Health Science in Tokyo, voices doubts common among developmental scientists when she says that the proposed institute for developmental biology and regenerative medicine may not provide "the right mix to stimulate basic research."

For RIKEN, the new institutes pose a host of other questions. Over the past 15 years, and starting with the inauguration of the Tsukuba life science facility in 1986, RIKEN has served as a convenient tool for the STA to diversify its biomedical research activities. This has left RIKEN with an unusual organizational structure in which personnel and funding within its main laboratories are out-numbered by those in loosely attached institutes and programs. And because of strict regulations on the overall number of government employees, new positions are short-term contracts. This has created difficulties in hiring group leaders at RIKEN's Brain Science Institute (BSI), which functions as an organizational model for the proposed institutes.

According to BSI Director Masao Ito, negotiations with RIKEN's other facilities on the transfer of tenured positions to BSI are under way. But such negotiations are thought likely to increase tensions between RIKEN's main laboratories and the new institutes.

ROBERT TRIENDL, TOKYo

\section{Japanese press calls for female promotion} stantial expansion of biomedical programs at the Institute of Physical and Chemical Research (RIKEN), which will include new institutes in developmental biology and regenerative medicine as well as in applied medical genetics, focusing on SNP database development. According to an STA spokesperson, each of the new institutes will be funded by $¥ 10$ billion annually and will employ around 100

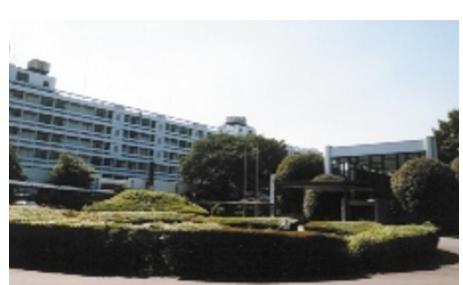
RIKEN laboratories
Japanese newspapers are urging the government to promote the recruitment of women civil servants, particularly within universities and research institutes, when drafting its new five-year plan. At present there is no such wording in the plan despite the fact that a new equal opportunities law was passed this summer.

According to official statistics, women represent only 12 perfull-time researchers. In addition, RIKEN will receive funding for a new embryo facility to be set up at its Tsukuba research center.

Although the new institutes were endorsed in a June report by an expert cent of the academic workforce in Japanese universities, and this figure drops to less than seven percent at the full professor level. The situation is even worse in the science and engineering departments of the major national univer- sities and research institutes, where female faculty members are rare. Only one of 100 chief scientists and group leaders at the various facilities within the Institute of Physical and Chemical Research (RIKEN) is female. And it was only this year that the first female scientist was awarded a grant under the prestigious ERATO program-a decade-long funding scheme.

"If you are ambitious, there is not much choice for women in Japanese science," says one female researcher who recently left Japan for a position at Johns Hopkins University: "Either you are the wife or the daughter of a prominent scientist, or you collaborate with a man who has sufficient influence to advance your career. Otherwise you end up at the lowest level of the hierarchy."

Robert TriendL, TOKyo 